\title{
BMJ Open Cohort profile: the MCC-Spain follow- up on colorectal, breast and prostate cancers: study design and initial results
}

\author{
Jessica Alonso-Molero (10 , ${ }^{1}$ Antonio J Molina, ${ }^{2}$ Jose Juan Jiménez-Moleón, ${ }^{3,4}$ \\ Beatriz Pérez-Gómez (D) , 3,5,6 Vicente Martin, ${ }^{2,3}$ Victor Moreno, ${ }^{3,7,8}$ Pilar Amiano, 3,9 \\ Eva Ardanaz, ${ }^{3,10,11}$ Silvia de Sanjose, ${ }^{3,7}$ Inmaculada Salcedo, ${ }^{3,4}$ \\ Guillermo Fernandez-Tardon, ${ }^{3,12}$ Juan Alguacil,, ${ }^{3,13}$ Dolores Salas, ${ }^{3,14}$ \\ Rafael Marcos-Gragera, ${ }^{3,15}$ Maria Dolores Chirlaque, ${ }^{3,16}$ Nuria Aragonés, ${ }^{3,17}$ \\ Gemma Castaño-Vinyals, 3,18,19,20 Marina Pollán, 3,5,6 Manolis Kogevinas,, 3, 18,19,20 \\ Javier Llorca ${ }^{1,3}$
}

To cite: Alonso-Molero J, Molina AJ, Jiménez-Moleón JJ, et al. Cohort profile: the MCC-Spain follow-up on colorectal, breast and prostate cancers: study design and initial results. BMJ Open 2019;9:e031904. doi:10.1136/ bmjopen-2019-031904

- Prepublication history and additional material for this paper are available online. To view these files, please visit the journal online (http://dx.doi. org/10.1136/bmjopen-2019031904).

JA-M, AJM and JJJ-M contributed equally.

Received 24 May 2019 Revised 10 September 2019 Accepted 24 October 2019

Check for updates

(c) Author(s) (or their employer(s)) 2019. Re-use permitted under CC BY-NC. No commercial re-use. See rights and permissions. Published by BMJ.

For numbered affiliations see end of article.

Correspondence to Dr Jessica Alonso-Molero; alonsomoleroj@gmail.com

\section{ABSTRACT}

Purpose Since 2016, the multicase-control study in Spain (MCC-Spain) has focused towards the identification of factors associated with cancer prognosis. Inception cohorts of patients with colorectal, breast and prostate cancers were assembled using the incident cases originally recruited.

Participants 2140 new cases of colorectal cancer, 1732 of breast cancer and 1112 of prostate cancer were initially recruited in 12 Spanish provinces; all cancers were incident and pathologically confirmed. Follow-up was obtained for 2097 (98\%), 1685 (97\%) and 1055 (94.9\%) patients, respectively.

Findings to date Information gathered at recruitment included sociodemographic factors, medical history, lifestyle and environmental exposures. Biological samples were obtained, and $80 \%$ of patients were genotyped using a commercial exome array. The follow-up was performed by (1) reviewing medical records; (2) interviewing the patients by phone on quality of life; and (3) verifying vital status and cause of death in the Spanish National Death Index. Ninetyseven per cent of recruited patients were successfully followed up in 2017 or 2018; patient-years of followup were 30914 . Most colorectal cancers $(52 \%)$ were at clinical stage II or lower at recruitment; 819 patients died in the follow-up and the 5-year survival was better for women (74.4\%) than men (70.0\%). $71 \%$ of breast cancers were diagnosed at stages I or II; 206 women with breast cancer died in the follow-up and the 5 -year survival was $90.7 \%$. $49 \%$ of prostate cancers were diagnosed at stage II and $32 \%$ at stage III; 119 patients with prostate cancer died in the follow-up and the 5-year survival was $93.7 \%$.

Future plans MCC-Spain has built three prospective cohorts on highly frequent cancers across Spain, allowing to investigate socioeconomic, clinical, lifestyle, environmental and genetic variables as putative prognosis factors determining survival of patients of the three cancers and the inter-relationship of these factors.

\section{Strengths and limitations of this study}

- 4837 incident cases of cancer (2097 colorectal; 1685 breast; 1055 prostate) have been prospectively followed up, accounting for more than 30000 patient-years and with only 153 patients $(3 \%)$ lost to follow-up.

- The cohort covers a wide spectrum of the Spanish population including 23 hospitals across Spain.

- A major strength of this study is the amount of information gathered at diagnosis, including sociodemographic, lifestyle, nutrition, familial and personal medical history, reproductive history, use of drugs, sleep, genotyping, clinical and pathological characteristics of the tumour, first-line treatment, side effects, health-related quality of life, and current vital status.

- Biological samples obtained at recruitment (tumour specimen, blood or saliva, toenail, hair and urine) will allow further investigations on metabolomics, epigenetics and exposure to chemicals such as metals.

- The multicentre characteristic of the study allows the evaluation of a wide geographical basis and increases the representativeness of the recruited sample, but it also may introduce heterogeneity in the information gathered and in treatment.

\section{INTRODUCTION}

Tumour size, node infiltration, metastasis, histology, clinical stage and cancer subtype continue to be the main prognosis factors in patients with cancer in spite of the evolving first-line treatment. ${ }^{1-5}$ Little effort, however, has been paid to examine the impact on survival of patient factors, such as lifestyle, genetics or environmental, together with tumour features and treatment.

Large prospective cohort studies on cancer focus on identifying risk factors, ${ }^{6}$ while 
clinical cohorts on cancer survival usually aim to analyse survival relationships with tumour properties, firstline treatment or patient characteristics. For instance, Lagendijk et $a l^{7}$ analysed data on 129692 women with breast cancer from the Netherlands Cancer Registry to compare breast conserving therapy and mastectomy in subgroups according to age at diagnosis, stage, systemic therapy, comorbidity, oestrogen/progesterone receptors and Her2 status. Cardwell et al linked the National Cancer Data Repository to the UK Clinical Practice Research Datalink and mortality data from the Office for National Statistics to investigate if statin use after colorectal cancer diagnosis was associated with better prognosis. Pettersson et a ${ }^{\ominus}$ studied survival after prostate cancer diagnosis in 121392 Swedish men from the Prostate Cancer data Base Sweden V.3.0, where data were available on age, stage, grade, prostate-specific antigen (PSA) level, model of detection, comorbidity, educational level and primary treatment. ${ }^{9}$ It is noteworthy that these cohorts were based on cancer registries, where data availability is usually restricted to demographic variables (sometimes including educational level and deprivation), tumour characteristics and few data on comorbidities or healthy habits. A different approach has been the use of the Surveillance, Epidemiology and End Results (SEER) database to retrospectively analyse survivorship with breast cancer, ${ }^{10}$ colorectal cancer ${ }^{11}$ or prostate cancer, ${ }^{12}$ but although the number of participants could be over 100000 , available data are restricted to those recorded for the general purposes of the SEER programme, not specifically for studying survivorship with cancer.

The multicase-control study in Spain (MCC-Spain) includes three prospective cohorts of patients with cancer (colorectal, female breast and prostate) with the aim to investigate long-term survival factors, including cancer characteristics and treatment, but also genetics and other omics, lifestyle (physical activity, nutrition, sleep, toxic habits), occupational exposures (including night shift work), environmental factors such as living area conditions, and medical history, aiming to build integrative prognosis models. This multidisciplinary study will provide a complete evaluation of the biological, clinical, environmental, lifestyle and socioeconomic factors determining survival of patients of the three cancers and of the inter-relationship of these factors. The following are the specific objectives for each cohort: For the colorectal cancer cohort: (1) to study the accomplishment of primary treatment with ESMO (European Society for Medical Oncology) and ASCO (American Society of Clinical Oncology) guidelines and factors associated with it; (2) to study factors associated with survivorship, response to treatment and toxicity due to chemotherapy using genetic, epidemiological and clinical-pathological variables; and (3) to validate those models via comparison with Glasgow Prognostic Score predictions. For the breast cancer cohort: (1) to study whether first-line treatment accomplished the St Gallen International Expert Consensus recommendations; (2) to study factors associated with survivorship, response to treatment and toxicity due to chemotherapy using genetic, epidemiological and clinical-pathological variables; and (3) to validate those models via comparison with the Nottingham Prognostic Index and Adjuvant! For prostate cancer cohort: (1) to analyse the adequacy of initial treatment to the recommendations by the European Association of Urology and the National Institute for Health and Care Excellence; (2) to elaborate models on survivorship, risk of biochemical relapse, quality of life, response to primary treatment and toxicity to chemotherapy/brachytherapy; and (3) to validate survivorship and risk of biochemical relapse models via comparison with Han and Kattan nomograms. In this article, we report the study design, the main description of all three cohorts and the preliminary results on survival.

\section{COHORT DESCRIPTION AND METHODS}

The MCC-Spain began as a case-control study in 2008, started by the Consortium for Biomedical Research in Epidemiology and Public Health (CIBERESP), on both genetic and environmental exposures associated with colorectal, female breast, prostate and gastric cancers and chronic lymphocytic leukaemia. Its design has been published elsewhere ${ }^{13}$; it recruited 10183 incident cases and controls between 2008 and 2013 in 12 Spanish provinces (Asturias, Barcelona, Cantabria, Girona, Granada, Gipuzkoa, Huelva, León, Madrid, Murcia, Navarra and Valencia). Using the incident cases originally recruited between 2008 and 2013, and given that in 2016 the MCCSpain has turned towards the identification of factors associated with cancer prognosis, inception cohorts on colorectal, breast and prostate cancers have been assembled, enrolling the patients for a prospective follow-up carried out in 2017-2018. From here on, we only refer to the recruited cases of colorectal (2140 cases), breast (1738 cases) and prostate (1112 cases) cancers; their distribution by province and hospital appears in online supplementary table 1 and the flow chart appears in figure 1.

\section{Patient recruitment and public involvement statement}

Patients recruited were between 20 and 85 years old, had resided in the catchment area for at least 6 months before the recruitment and were able to answer the epidemiological questionnaire, and had incident colorectal, breast or prostate cancer. For the recruitment, study personnel contacted newly diagnosed cancer cases in the 21 collaborating hospitals. Cases were identified as soon as possible after the diagnosis; only histologically confirmed incident cases were included.

Participants are being informed on the project's main results via flyers. There is no other patient involvement.

\section{Information at recruitment and biological samples}

The information obtained and its timing is summarised in table 1. 


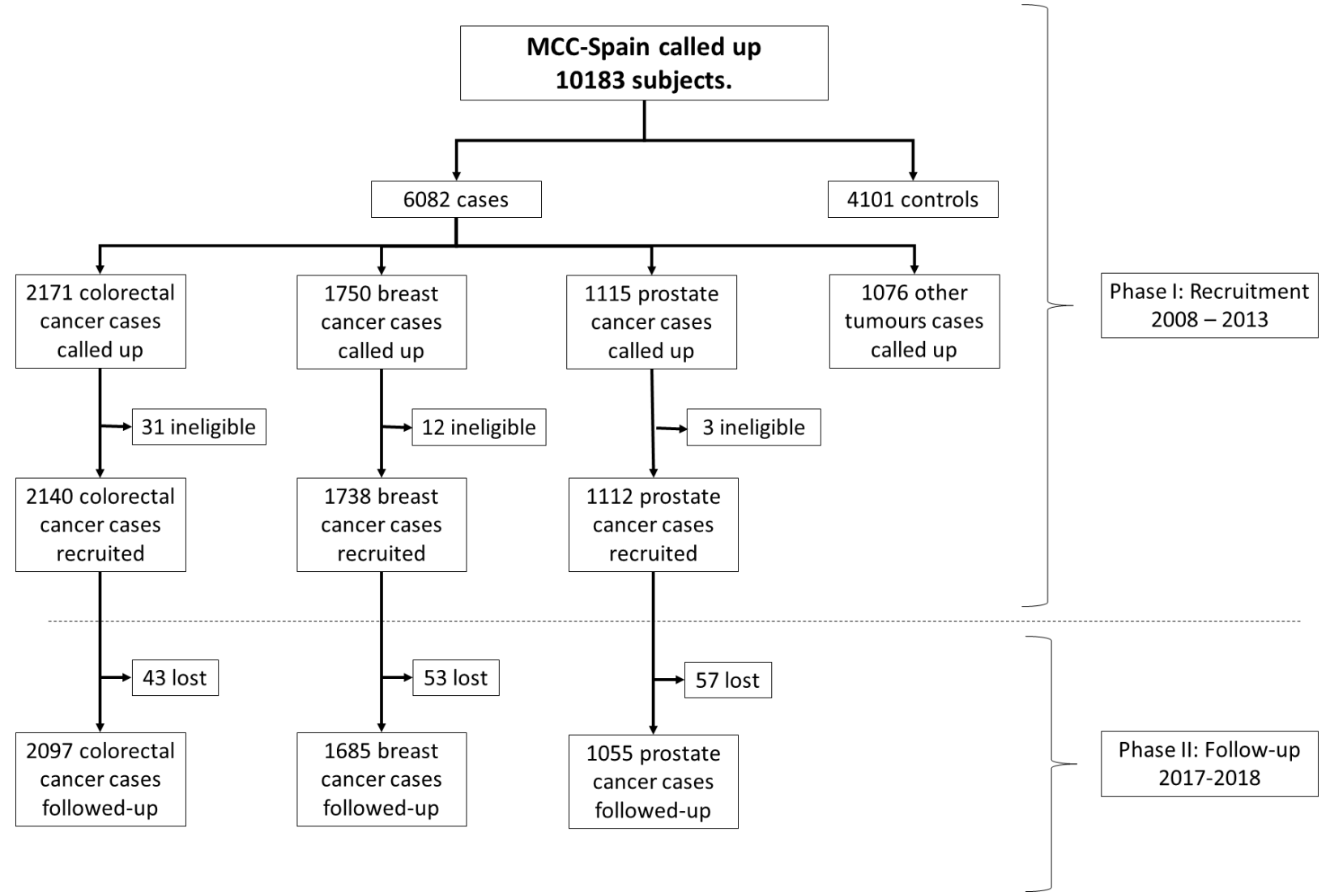

Figure 1 Flow chart of the participants in the MCC-Spain study. MCC-Spain, multicase-control study in Spain.

Information about sociodemographic, personal and familial medical history, use of drugs, reproductive history, physical activity, and environmental and occupational exposures was gathered using a standardised questionnaire $^{14}$ administered by trained personnel in a face-to-face interview. Diet information in the year before diagnosis was obtained using a validated semiquantitative frequency-food questionnaire ${ }^{15}$ filled by the participants. Both questionnaires can be found at http:// www.mccspain.org. Biological samples were obtained, including peripheral blood or saliva (from 92\% of breast cancer cases, $95 \%$ of colorectal cancer cases and $97 \%$ of prostate cancer cases), toenail and hair (from $77 \%$ and $81 \%$ of participants, respectively), urine or tumour biopsies. Regarding peripheral blood, $27 \mathrm{~mL}$ was aliquoted in whole blood, plasma, serum and cellular fraction for DNA extraction and stored at $-80^{\circ} \mathrm{C}$. Saliva was collected from people unable to donate a blood sample.

\section{Genotyping}

From $80 \%$ of the participants, a genotype of exome was made using the Illumina Infinium HumanExome. In addition to the about 250000 exome variants included in the original beadchip, 6000 SNPs previously found in GWAS (Genome-wide Association Study) or localised in metabolic pathways of interest were added on MCC-Spain researchers' request. MCC-Spain has recently obtained funding for carrying out a GWAS with all the participants and to launch an analysis on circulant microRNA in patients with breast cancer.

\section{Initial clinical information}

Trained personnel reviewed the medical records in order to collect information on pathology characteristics, tumour extension, clinical data, first-line treatment and recurrence. For colorectal cancer cases, we documented the first biopsy, tumour location, surgical piece dimensions, histological type according to the International Classification of Diseases for Oncology, Third Edition, tumour, node, metastases (TNM) status, carcinoembryonic antigen levels, and first-line treatment (surgery extension, if done; neoadjuvant, adjuvant or palliative chemotherapy or radiotherapy). For breast cancers, we obtained information on tumour location, differentiation's degree, immunohistochemical characteristics (hormonal receptors, Erb-B2), TNM status and first-line treatment (mastectomy/conservative surgery; neoadjuvant, adjuvant or palliative hormonotherapy, chemotherapy or radiotherapy; target-directed therapy such as trastuzumab). For prostate cancer cases, we gathered information on tumour location, Gleason score, D'Amico classification, TNM status, PSA levels and firstline treatment (none, surgery, hormonotherapy, chemotherapy or radiotherapy, including, when appropriate, the purpose of therapy-neoadjuvant, adjuvant or palliative). TNM status for all three tumours was classified according to TNM sixth edition. 
Table 1 Information obtained in the MCC-Spain

\begin{tabular}{|c|c|c|c|}
\hline Phase & & \multicolumn{2}{|l|}{ Measurements } \\
\hline \multirow{7}{*}{$\begin{array}{l}\text { Phase I: } \\
\text { recruitment }\end{array}$} & \multirow{7}{*}{$\begin{array}{l}2008- \\
2013\end{array}$} & \multicolumn{2}{|c|}{ Contact with newly diagnosed cancer cases. } \\
\hline & & \multicolumn{2}{|c|}{$\begin{array}{l}\text { Trained personnel perform a structured computerised epidemiological questionnaire in a } \\
\text { face-to-face interview to obtain the following information: sociodemographic, personal and } \\
\text { familial medical history, use of drugs, reproductive history, physical activity, environmental and } \\
\text { occupational exposures. }\end{array}$} \\
\hline & & \multicolumn{2}{|c|}{$\begin{array}{l}\text { A validated semiquantitative frequency-food questionnaire is self-completed to obtain diet } \\
\text { information. }\end{array}$} \\
\hline & & \multirow{3}{*}{\multicolumn{2}{|c|}{$\begin{array}{l}\text { Biological samples are obtained: peripheral blood or saliva, toenail, hair, urine, tumour biopsies. } \\
\text { A genotype of exome is made using the Illumina Infinium HumanExome. } \\
\text { Medical records review by trained personnel to obtain the following: pathology characteristics, } \\
\text { tumour extension, clinical data, first-line treatment, recurrence. }\end{array}$}} \\
\hline & & & \\
\hline & & & \\
\hline & & For prostate cancer cases & Gleason score, D’Amico classification, PSA levels. \\
\hline \multirow{7}{*}{$\begin{array}{l}\text { Phase II: follow- } \\
\text { up }\end{array}$} & \multirow{7}{*}{$\begin{array}{l}2017- \\
2018\end{array}$} & \multicolumn{2}{|c|}{ Medical records review by trained personnel to obtain the following: } \\
\hline & & For colorectal cancer cases & $\begin{array}{l}\text { TNM status at recruitment, first-line treatment, surgical } \\
\text { margins, patient status after first-line treatment, } \\
\text { appearance of second primary tumour, current patient's } \\
\text { vital status. }\end{array}$ \\
\hline & & For breast cancers cases & $\begin{array}{l}\text { Histological grade at diagnosis, Nottingham index, } \\
\text { complete clinical/pathological remission, grade of response } \\
\text { to treatment, relapse, second primary tumour, current } \\
\text { patient's vital status. }\end{array}$ \\
\hline & & \multicolumn{2}{|c|}{ Contact by phone to complete specific quality of life questionnaires. } \\
\hline & & For colorectal cancer cases & SF-12, FACT-Colorectal Symptom Index. \\
\hline & & For breast cancer cases & SF-12, FACT/NCCN Breast Symptom Index. \\
\hline & & For prostate cancer cases & $\begin{array}{l}\text { SF-12, Charlson Comorbidity Index, FACT-P questionnaire, } \\
\text { International Prostate Symptom Score. }\end{array}$ \\
\hline
\end{tabular}

SF-12: 12-Item Short Form Survey; FACT: Functional Assessment of Cancer Therapy (P for prostate, B for breast cancer); FACT/NCCN: Functional Assessment of Cancer Therapy/National Comprehensive Cancer Network. IND, Índice Nacional de Defunciones; MCC-Spain, multicase-control study in Spain; PSA, prostate-specific antigen; TNM, tumour, node, metastases.

\section{Follow-up information}

Follow-up was carried out between 2017 and 2018 by reviewing medical records. For patients with colorectal cancer, we collected data on TNM status at recruitment, first-line treatment, surgical margins, patient status after first-line treatment (free of disease, partial response, progression, relapse or stable disease), appearance of second primary tumour and current patient's vital status. For patients with breast cancer, we gathered information on histological grade at diagnosis, Nottingham index, complete clinical/pathological remission, grade of response to treatment (according to the Miller and Payne system or similar classifications), relapse, second primary tumour and current patient's vital status. For patients with prostate cancer, the information assembled included PSA concentration, Gleason grade and biopsy characteristics at diagnosis, pathological characteristics of the surgical specimen, first-line treatment, clinical response to first-line treatment (stable disease/progression or relapse/unknown), chemical relapses, relapse clinical 
characteristics (local/metastatic and its location), second primary tumour, and current patient's vital status. Some of these data were obtained in order to double-check the clinical information collected at recruitment.

The National Death Index (Índice Nacional de Defunciones (IND)) was consulted to realise the vital status of patients whose last contact with the hospital had occurred 3 or more months before our revision of his/her medical record. The IND is a nationwide database supported by the Spanish Ministry of Health; it is intended to allow the researchers to establish the vital status of patients under study. ${ }^{16}$

Patients alive at follow-up were contacted by phone and asked to complete specific quality of life questionnaires: SF-12 ${ }^{17}$ (12-Items Short Form Survey; colorectal, breast and prostate cancers), FACT-Colorectal Symptom Index ${ }^{18}$ (Functional Assessment of Cancer Therapy; colorectal cancer), FACT/NCCN (National Comprehensive Cancer Network) Breast Symptom Index ${ }^{19}$ (breast cancer), and for prostate cancer the Charlson Comorbidity Index, ${ }^{20}$ the FACT-P questionnaire (Functional Assessment of Cancer Therapy Prostate) ${ }^{21}$ and the International Prostate Symptom Score. ${ }^{22}$

The number of patients with follow-up is 2097 for colorectal, 1685 for breast and 1055 for prostate cancer cohorts. This gives a $91 \%$ statistical power for colorectal cancer to detect an HR $\geq 1.2$; an $83 \%$ statistical power for breast cancer to detect the same HR; and an $80 \%$ statistical power for prostate cancer to detect an HR $\geq 1.25$ (assuming 20\% exposed patients and 75\%, 90\% and $85 \%$ survival probability in the non-exposed group, respectively).

\section{Statistical analysis}

For preliminary results shown in this paper, data are described using absolute frequencies with percentages and means with SD. Patients who died by any cause before the end of follow-up were classified as events and censored otherwise. Time of follow-up was the difference between date of diagnosis and date of death or date of last contact with the hospital or the researchers. Survival probabilities were obtained using unadjusted KaplanMeier estimators. Further analyses should deal with confounding and modifiers using multivariate regression models (eg, Cox or Weibull regression). Initial treatment could be related with both basal factors and survivorship, eventually leading to confounding by indication; it would be controlled using propensity scores.

\section{Ethics}

The protocol of MCC-Spain was approved by the ethics committees of the participating institutions. ${ }^{13}$ At recruitment, all participants were informed about the study objectives and signed an informed consent, which also included the authorisation for following up the patient via medical records or phone calls. Only participants agreeing to being followed up were included in the inception cohorts. Confidentiality of data is secured by removing personal identifiers in the data sets. The database was registered in the Spanish Agency for Data Protection (number 2102672171).

\section{FINDINGS TO DATE}

The MCC-Spain has provided results on the effects of different risk factors. For instance, night shift work increased the risk of more aggressive prostate cancers, ${ }^{23}$ although this excess risk almost disappeared 20 years after last exposure ${ }^{24}$; long-term consumption of calcium channel blockers was associated with higher breast cancer risk in overweight women ${ }^{25}$; adherence to the Western dietary patterns increased breast cancer risk in both premenopausal and postmenopausal women ${ }^{26}$; first validation in a European population of a risk model for breast cancer developed in American women using both modifiable and non-modifiable risk factors as well as 92 genetic variants ${ }^{27}$; use of environmental and genetic factors to elaborate a model to stratify the risk of colorectal cancer ${ }^{28}$; and adherence to the World Cancer Research Fund/American Institute for Cancer Research nutrition-based guidelines was associated with lower risk of colorectal and breast cancers, but not of prostate cancer. ${ }^{29}$ A complete list of published results from MCC-Spain appears in online supplementary table 2 and supplementary reference list.

Initial results of the follow-up are shown in this work. Table 2 displays the main characteristics of the patients; table 3 details specific information of each tumour; and table 4 describes first-line treatment.

\section{Colorectal cancer}

Out of 2140 patients with colorectal cancer, 2097 (98\%) have been followed. They were $67 \pm 10.9$ years old on average at recruitment, and $1334(63.4 \%)$ were men. The first case was recruited on 18 March 2007 and the follow-up was closed on 23 August 2018, accounting for 12813.8 person-years of follow-up. During this period, $819(39.1 \%)$ cases died. Linearised mortality rate was 6.4 per 100 patient-years (95\% CI 6.0 to 6.8) (table 2).

Most cases $(1882,90 \%)$ were adenocarcinoma, and the most frequent location was rectum-sigma (37.7\%) and the less frequent right colon (27\%). Of the patients, $52 \%$ were at clinical stage II or lower, and in 110 patients (5.3\%) we could not establish the clinical stage. Of the cancers, $52.5 \%$ were moderately differentiated (grade II) and $24.8 \%$ well differentiated (grade I) (table 3 ).

Surgery was carried out in 1999 patients with colorectal cancer, and it was for palliative purposes in 127 patients $(6.1 \%)$. There were 169 patients who were treated via endoscopy, reaching complete resection in 107 of them. There were 1518 (72.4\%) patients who received chemotherapy, and most of them (1451) were for adjuvant or neoadjuvant purposes; $488(23.2 \%)$ received radiotherapy (401 neoadjuvant, 82 adjuvant and only 5 palliative) (table 4). 
Table 2 Main characteristics of the followed patients

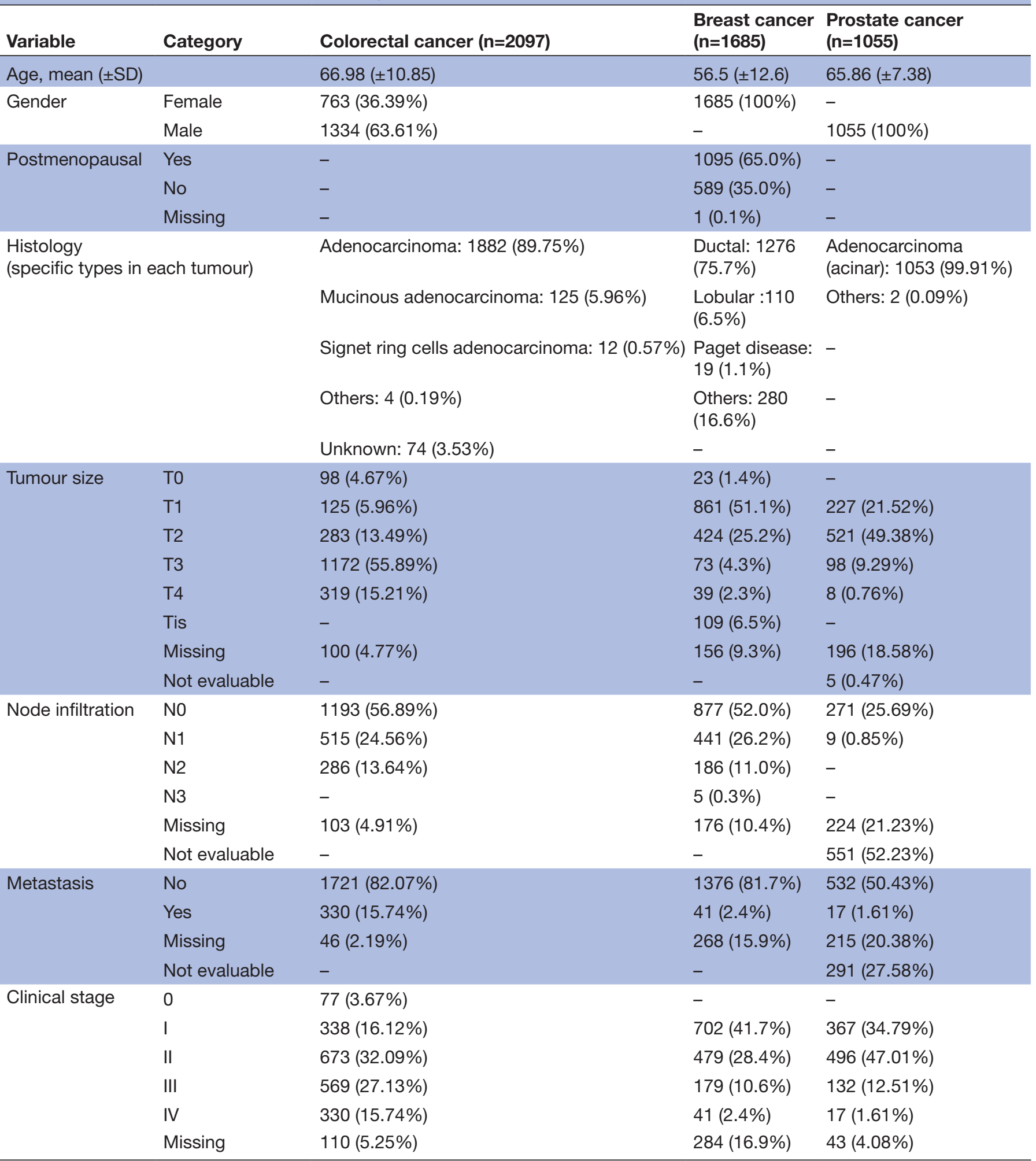

The 5-year survival probability estimated via KaplanMeier was $71.6 \%$ (95\% CI 69.6 to 73.5) (figure 2A). Survival was higher in women $(74.4 \%, 95 \%$ CI 71.0 to $77.2)$ than in men $(70.0 \%, 95 \%$ CI 67.5 to 72.4$)(\mathrm{p}<0.001)$ (figure 2B). The 5-year survival probability was $85.2 \%$ (81.0-88.6) in patients diagnosed with stage I, 84.0\%
(81.0-86.6) with stage II, $73.4 \%$ (69.6-76.9) with stage III and $27.6 \%$ (22.9-32.5) with stage IV (figure 3A).

\section{Breast cancer}

The maximum span for breast cancer follow-up was 9.5 years (from 13 July 2007 to 22 March 2017). Follow-up 


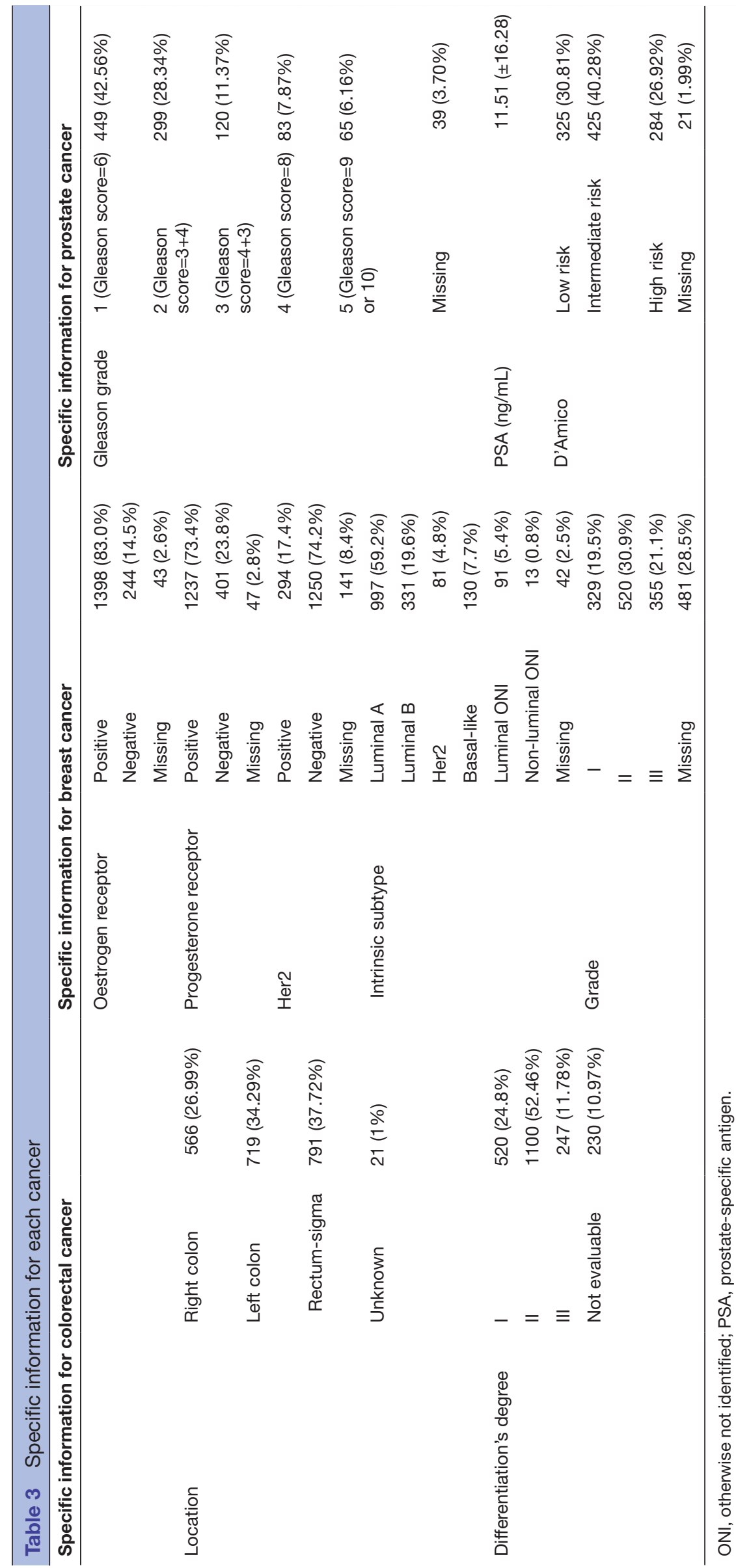


Table 4 First-line treatment

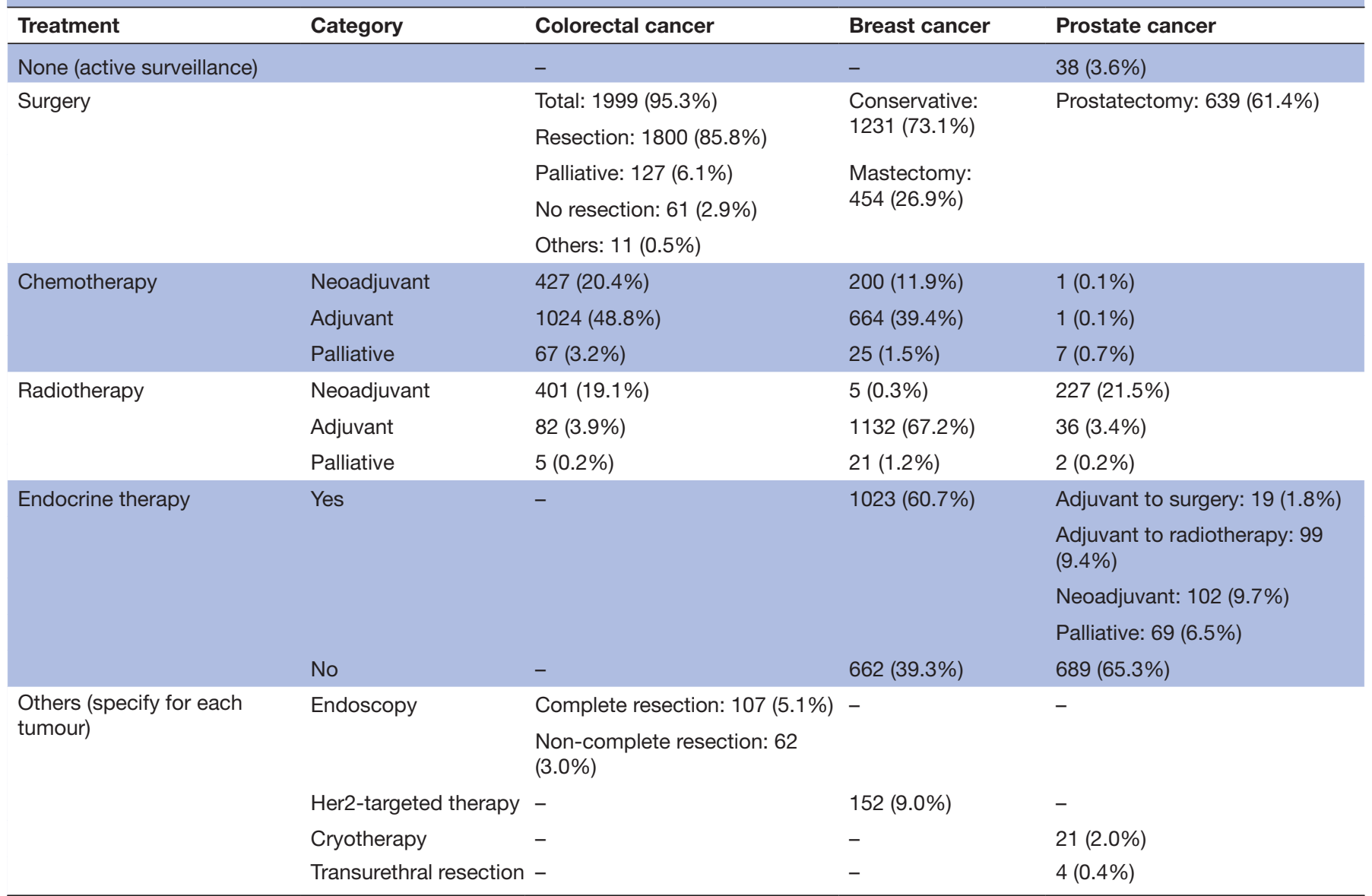

was obtained for 1685 out of 1738 patients with breast cancer (97\%), adding 10931 person-years; 206 patients died in the follow-up. The linearised mortality rate was 1.9 per 100 patient-years (95\% CI 1.6 to 2.2).

Women with breast cancer were $56.5 \pm 12.6$ years old on average at recruitment, and $65 \%$ were postmenopausal. The most usual type of tumour was ductal $(75.7 \%)$, followed by lobular $(6.5 \%)$. Most breast cancers were diagnosed at early stages $(71 \%$ at stages I or II) and only $41(2.4 \%)$ had metastasised at the time of diagnosis (table 2). Of the cancers, $83 \%$ were oestrogen receptorpositive, $73.4 \%$ progesterone receptor-positive and 17.4\% Her2-positive. Regarding intrinsic subtypes, 997 $(59.2 \%)$ could be classified as luminal A, $331(19.6 \%)$ as luminal B, $81(4.8 \%)$ as Her2 and $130(7.7 \%)$ as basallike. According to grade of differentiation, moderately differentiated accounted for $30.9 \%$ of breast cancers, and well differentiated and bad differentiated accounted for about $20 \%$ of cancers each. Grade could not be obtained from medical records in 481 patients $(28.5 \%$ ) (table 3 ).

Conservative surgery was performed in $1231(73.1 \%)$ patients and mastectomy in the remaining 454 (26.9\%). Adjuvant or neoadjuvant chemotherapy was administered to $50.3 \%$ of patients, while radiotherapy was used in 1158 women $(68.7 \%)$, endocrine therapy was used in 1023 women $(60.7 \%)$ and Her2-targeted therapy in 152 patients $(9.0 \%)$ (table 4$)$. Kaplan-Meier 5-year survival with breast cancer was $90.7 \%$ (95\% CI 89.2 to 92.0$)$ (figure 2C). Women diagnosed with stage I had $97 \%$ (95.5-98.1) 5-year survival probability, 91.9\% (89.1-94.1) at stage II, $84.1 \%(77.8-88.7)$ at stage III and $38.5 \%$ (18.6-58.2) at stage IV (figure 3B).

\section{Prostate cancer}

A total of 1112 men with prostate cancer were recruited and $1055(94.9 \%)$ have been followed up. The first patient was included on 26 January 2008 and the end of follow-up was on 13 July 2018, adding 7169.6 person-years of follow-up. Patients were 65.9 years old on average at recruitment. There were 119 patients who died in the follow-up, making the linearised mortality rate 1.7 per 100 patient-years (95\% CI 1.4 to 2.0$)$.

Almost all prostate cancers $(99.9 \%)$ were adenocarcinoma; 496 (47\%) were diagnosed at stage II and 132 $(12.5 \%)$ at stage III (table 2$)$. The level of PSA gives an average of $11.5 \pm 16.3 \mathrm{ng} / \mathrm{mL}$. Considering the Gleason score, $42.6 \%$ of prostate cancers were well differentiated (Gleason grade $=1$, ie, Gleason score $=6$ ), $28.3 \%$ were at Gleason grade 2 (Gleason score=3+4), and only $14.0 \%$ were bad differentiated (Gleason grade 4 or 5, ie, Gleason score $\geq 8$ ). Gleason grade could not be established in $17.4 \%$ of patients. D'Amico classification system results in $31.4 \%$ of patients with low-risk cancer, $41.1 \%$ intermediate-risk and $27.4 \%$ high-risk cancer (table 3). 

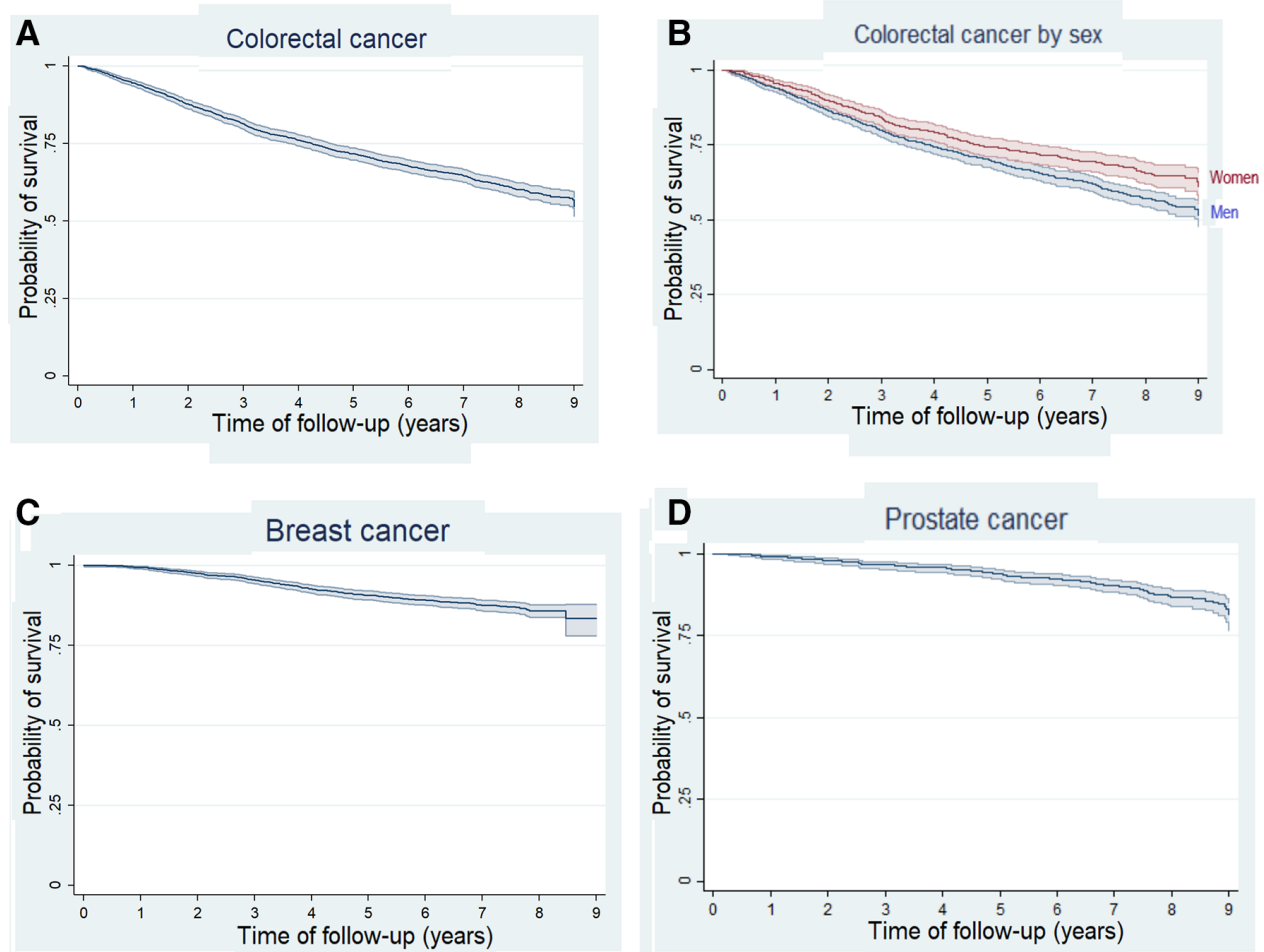

Figure 2 Kaplan-Meier survival estimates for colorectal cancer (A), colorectal cancer by sex (B), breast cancer (C) and prostate cancer (D).

Thirty-eight patients with prostate cancer were not treated medically at the beginning, being followed by active surveillance. Prostatectomy was performed in $61.4 \%$ cases, radiotherapy in 265 patients $(25.1 \%)$ and endocrine therapy in 289 patients (27.4\%). A small number of patients were treated via transurethral resection, cryotherapy or chemotherapy (table 4). The 5-year survival probability by Kaplan-Meier was $93.7 \%$ (95\% CI 92.0 to 95.1 ) (figure 2D). Survival probability 5 years after being diagnosed was $94.5 \%$ (88.1-97.5) for patients at stage I, 95.6\% (93.3-97.2) at stage II, 92.4\% (88.5-95.0) at stage III and $70.5 \%(42.8-88.6)$ at stage IV (figure 3C).

\section{STRENGTHS AND LIMITATIONS}

In this article, we have described how three prospective cohorts on colorectal, breast and prostate cancers have been assembled from patients originally recruited for a case-control study, with $97 \%$ patients followed up and accounting for more than 30000 person-years. This is a main achievement of a network settled within the CIBERESP in 12 Spanish provinces. The study is population-based and included only incident cancers. The amount of detailed information recorded as well as the availability of biological samples at recruitment will allow the identification of genetics, environmental, lifestyle and clinical prognosis factors in three frequent cancers in Spain. In this regard, a remarkable feature of the study is the feasibility of studying cancer risk factors as putative prognosis factors. For example, risk factors already analysed in the case-control phase were diet, circadian cycle disruption, some drugs, endocrine disruptors, artificial light or proximity to green spaces; information regarding these risk factors was recorded at recruitment and is available for a prognosis factor analysis in the follow-up (see online supplementary material for a complete reference list of MCC-Spain articles).

Obtaining information on personal history, occupational exposures, diet, physical exercise or other lifestyle components is somewhat subjective as both patients and interviewers could be prone to be influenced by their feelings or beliefs about the hypotheses under study, eventually leading to differential misclassification bias. This could hardly have occurred in this study. First, patients were not aware of the hypotheses. Second, interviewers were familiar with the case-control study, not with the cohort design as it was decided later; therefore, if interviewers or patients have introduced some misclassification, it could probably have been non-differential, eventually leading to bias towards the null, ${ }^{30}$ which would make more robust the positive findings in this cohort study.

This study also has some weaknesses. First, multicentre studies are double-edged; they are needed in order to include many patients, but they could introduce heterogeneity in both the information gathered and the way patients are treated. In this regard, the analysis of prognosis factors should be adjusted for the hospital of recruitment. Second, 113 participating patients have been lost ( 43 with colorectal cancer, 53 with breast cancer and 57 with prostate cancer). We have tried to minimise it by searching information in three ways: medical 

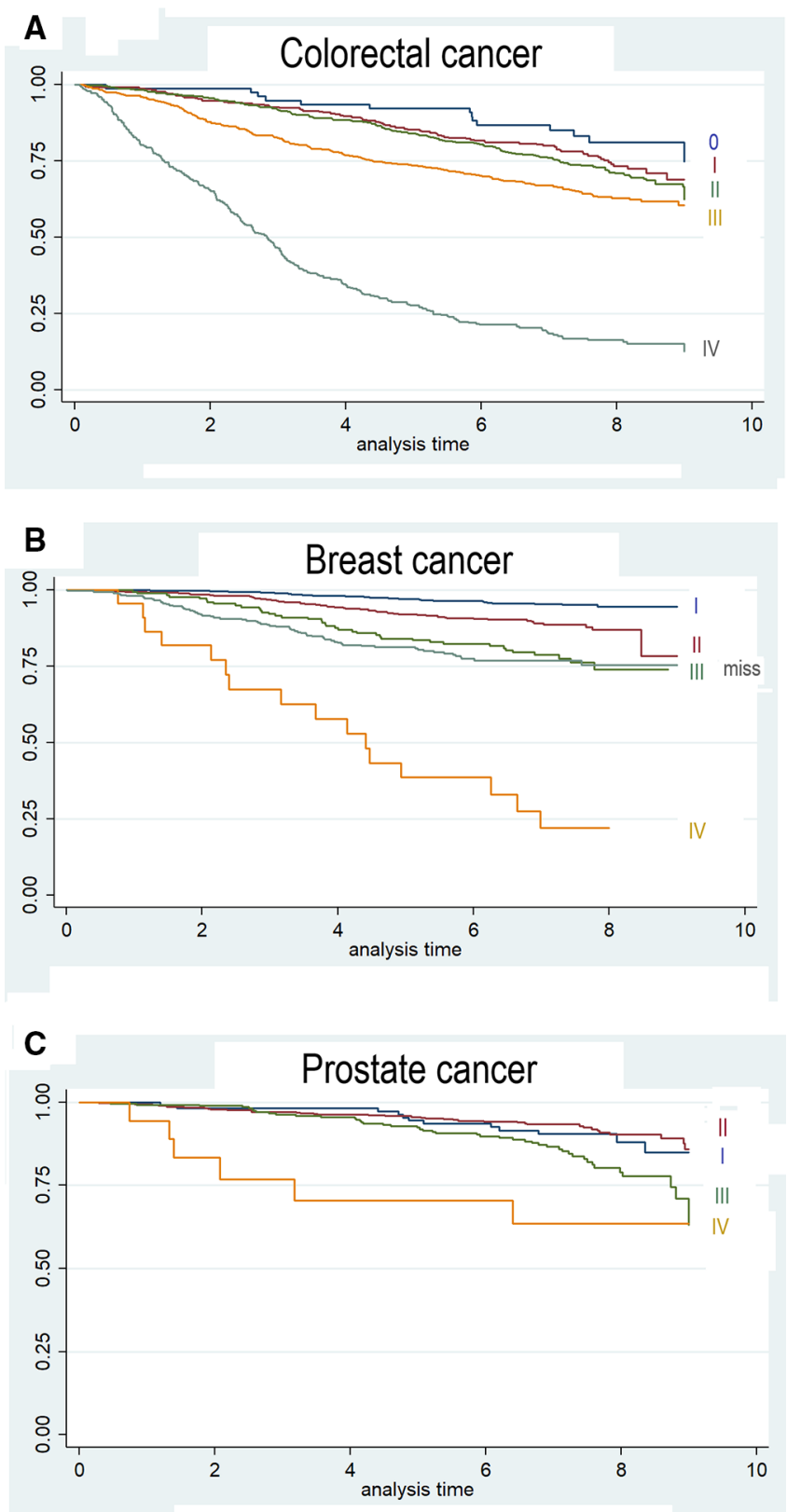

Figure 3 Kaplan-Meier estimates by stage at diagnosis for colorectal cancer (A), breast cancer (B) and prostate cancer (C).

records, phone calls and IND; however, we cannot rule out that some patients without follow-up could have died. It is noteworthy that, due to the small number of patients without follow-up, the maximum bias it could introduce in our survival estimates is $2 \%$ for colorectal cancer, $3 \%$ for breast cancer and $5 \%$ for prostate cancer. Third, we have not obtained information on lifestyle changes after diagnosis, which limits lifestyle analysis to habits before cancer appearance. Fourth, the number of patients included in our cohorts is small compared with those based on cancer registries, limiting the analysis of subgroups.

Summarising, the MCC-Spain study has assembled three cohorts with about 4700 patients with cancer accounting for 30000 patient-years of follow-up, with only $3 \%$ patient withdrawals. The information gathered at recruitment will allow to prospectively investigate clinical, lifestyle, environmental and genetic variables as prognosis factors in colorectal, breast and prostate cancers in Spain.

\section{Samples}

Biological samples were stored at the biobanks supported by Instituto de Salud Carlos III-FEDER: Parc de Salut MAR Biobank (MARBiobanc) (RD09/0076/00036), 'Biobanco La Fe' (RD 09 0076/00021) and FISABIO Biobank (RD09 0076/00058), and also at the Public Health Laboratory from Gipuzkoa, the Basque Biobank, the ICOBIOBANC (sponsored by the Catalan Institute of Oncology), the IUOPA Biobank from the University of Oviedo and the ISCIII Biobank.

\section{Collaborators}

MCC-Spain already participates in international consortiums such as Genetics and Epidemiology of Colorectal Cancer Consortium (GECCO; https://www.fredhutch. org/en/labs/phs/projects/cancer-prevention/projects/ gecco.html), Breast Cancer Association Consortium (BCAC; http://bcac.ccge.medschl.cam.ac.uk/) and Prostate Cancer Association Group to Investigate Cancer Associated Alterations in the Genome (PRACTICAL; http:// practical.icr.ac.uk/blog/), where MCC-Spain would contribute to study interactions among the putative prognosis factors in vast population samples.

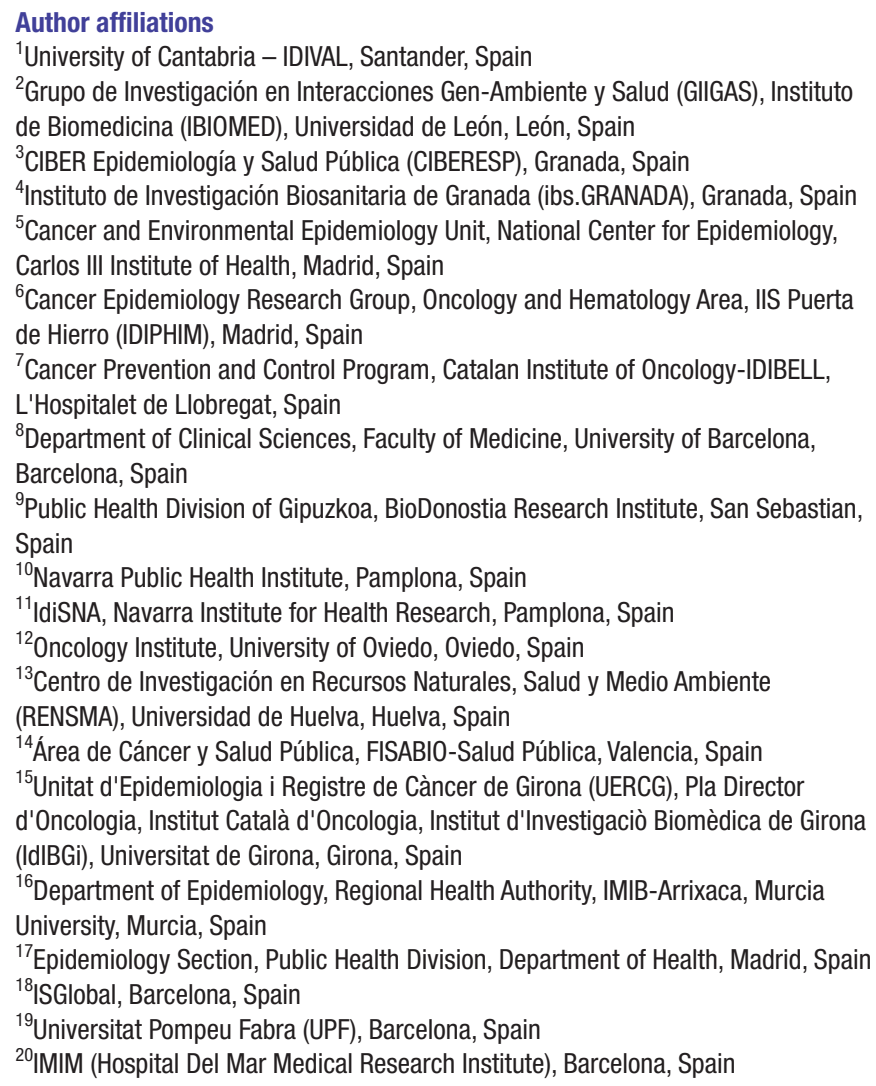

Acknowledgements We thank all the subjects who participated in the study and all MCC-Spain collaborators. SNP genotyping services were provided by the Spanish 'Centro Nacional de Genotipado' (CEGEN-ISCIII). 
Contributors JA, AJM, JJJ-M have contributed to the conception and design of the study, considering the same contribution. JAM, AJM, JJJ-M, BP-G, VMa, VMo, PA, EA, SdS, IS, GF-T, JA, DS, RM-G, MDC, NA, GC-V, MP, MK and JL have acquired the data and have been involved in drafting the manuscript. All of them read and approved the final manuscript.

Funding The study was partially funded by the 'Accion Transversal del Cancer', approved on the Spanish Ministry Council on 11 October 2007, by the Instituto de Salud Carlos III-FEDER (PI08/1770, PI08/0533, PI08/1359, PS09/00773-Cantabria, PS09/01286-León, PS09/01903-Valencia, PS09/02078-Huelva, PS09/01662Granada, Pl11/01403, Pl11/01889-FEDER, Pl11/00226, Pl11/01810, Pl11/02213, $\mathrm{Pl} 12 / 00488, \mathrm{Pl} 12 / 00265, \mathrm{Pl} 12 / 01270, \mathrm{Pl} 12 / 00715, \mathrm{Pl} 12 / 00150, \mathrm{Pl}$ 14/01219, Pl14/0613, Pl15/00069, Pl15/00914, Pl15/01032, Pl17CIII/00034, PI18/00181), by the Fundación Marqués de Valdecilla (API 10/09), by the ICGC International Cancer Genome Consortium CLL (the ICGC CLL-Genome Project is funded by Spanish Ministerio de Economía y Competitividad (MINECO) through the Instituto de Salud Carlos III (ISCIII) and Red Temática de Investigación del Cáncer (RTICC) del ISCIII (RD12/0036/0036)), by the Junta de Castilla y León (LE22A10-2), by the Consejería de Salud of the Junta de Andalucía (PI-0571-2009, PI-0306-2011, salud201200057018tra), by the Conselleria de Sanitat of the Generalitat Valenciana (AP_061/10), by the Recercaixa (2010ACUP 00310), by the Regional Government of the Basque Country, by the Consejería de Sanidad de la Región de Murcia, by the European Commission (grants F00D-CT-2006-036224-HIWATE), by the Spanish Association Against Cancer (AECC) Scientific Foundation (GCTRA18022MORE), by the Catalan Government-Agency for Management of University and Research Grants (AGAUR) (grants 2017SGR723 and 2014SGR850), by the Fundación Caja de Ahorros de Asturias, and by the University of Oviedo. ISGlobal is a member of the CERCA Programme, Generalitat de Catalunya.

Competing interests None declared.

Patient consent for publication Not required.

Provenance and peer review Not commissioned; externally peer reviewed.

Data availability statement Data are available upon reasonable request.

Open access This is an open access article distributed in accordance with the Creative Commons Attribution Non Commercial (CC BY-NC 4.0) license, which permits others to distribute, remix, adapt, build upon this work non-commercially, and license their derivative works on different terms, provided the original work is properly cited, appropriate credit is given, any changes made indicated, and the use is non-commercial. See: http://creativecommons.org/licenses/by-nc/4.0/.

\section{ORCID IDs}

Jessica Alonso-Molero http://orcid.org/0000-0002-1939-8798

Beatriz Pérez-Gómez http://orcid.org/0000-0002-4299-8214

\section{REFERENCES}

1 Saadatmand S, Bretveld R, Siesling S, et al. Influence of tumour stage at breast cancer detection on survival in modern times: population based study in 173797 patients. BMJ 2015;351.

2 Shukla N, Hagenbuchner M, Win KT, et al. Breast cancer data analysis for survivability studies and prediction. Comput Methods Programs Biomed 2018;155:199-208.

3 Mirza AN, Mirza NQ, Vlastos G, et al. Prognostic factors in nodenegative breast cancer. Ann Surg 2002;235:10-26.

4 Zhang Z-yu, Luo Q-feng, Yin X-wei, et al. Nomograms to predict survival after colorectal cancer resection without preoperative therapy. BMC Cancer 2016;16:1-21.

5 Merriel SWD, May MT, Martin RM. Predicting prostate cancer progression: protocol for a retrospective cohort study to identify prognostic factors for prostate cancer outcomes using routine primary care data. BMJ Open 2018;8:1-5.

6 Riboli E, Hunt KJ, Slimani N, et al. European Prospective Investigation into Cancer and Nutrition (EPIC): study populations and data collection. Public Health Nutr 2002;5:1113-24.

7 Lagendijk M, van Maaren MC, Saadatmand S, et al. Breast conserving therapy and mastectomy revisited: breast cancer-specific survival and the influence of prognostic factors in 129,692 patients. Int. J. Cancer 2018;142:165-75.
8 Cardwell CR, Hicks BM, Hughes C, et al. Statin use after colorectal cancer diagnosis and survival: a population-based cohort study. J Clin Oncol 2014;32:3177-83.

9 Pettersson A, Robinson D, Garmo H, et al. Age at diagnosis and prostate cancer treatment and prognosis: a population-based cohort study. Ann Oncol 2018;29:377-85.

10 Leone JP, Leone J, Zwenger AO, et al. Prognostic significance of tumor subtypes in women with breast cancer according to stage. Am $J$ Clin Oncol 2019;42:588-95.

11 Li Y, Feng Y, Dai W, et al. Prognostic effect of tumor sidedness in colorectal cancer: a SEER-Based analysis. Clin Colorectal Cancer 2019;18:e104-16.

12 Roy S, Morgan SC. Who dies from prostate cancer? an analysis of the surveillance, epidemiology and end results database. Clin Oncol 2019;31:630-6.

13 Castaño-Vinyals G, Aragonés N, Pérez-Gómez B, et al. PopulationBased multicase-control study in common tumors in Spain (MCCSpain): rationale and study design. Gaceta Sanitaria 2015;29:308-15.

14 Estudio MCC-Spain. Epidemiological questionnaire, 2010. Available: http://www.mccspain.org/wp-content/uploads/2016/07/Quest_ MCCSpain.pdf [Accessed 6 Sep 2019].

15 Estudio MCC-Spain. Semi-Quantitative frequency-food questionnaire, 2010. Available: http://www.mccspain.org/wpcontent/uploads/2016/04/03_Cuestionario-alimentario_09Nov09.pdf [Accessed 6 Sep 2019].

16 Navarro C. El Índice Nacional de Defunciones: un avance en La accesibilidad de Los datos de mortalidad largamente esperado. Gaceta Sanitaria 2006;20:421-3.

17 Ware J, Kosinki M, Turner-Bowker D, et al. How to score version 2 of the SF-12 health survey. Lincoln, RJ Qual Inc 2004.

18 Colwell HH, Mathias SD, Turner MP, et al. Psychometric evaluation of the fact colorectal cancer symptom index (FCSI-9): reliability, validity, responsiveness, and clinical meaningfulness. Oncologist 2010:15:308-16.

19 Garcia SF, Rosenbloom SK, Beaumont JL, et al. Priority symptoms in advanced breast cancer: development and initial validation of the National comprehensive cancer Network-Functional assessment of cancer Therapy-Breast cancer symptom index (NFBSI-16). Value Heal 2012;15:183-90.

20 Charlson ME, Pompei P, Ales KL, et al. A new method of classifying prognostic comorbidity in longitudinal studies: development and validation. J Chronic Dis 1987:40:373-83.

21 Esper P, Mo F, Chodak G, et al. Measuring quality of life in men with prostate cancer using the functionale assessment of cancer therapyprostate instrument. Adult Urol 1997;30:920-8.

22 Barry MJ, Fowler FJ, O'Leary MP, et al. The American urological association symptom index for benign prostatic hyperplasia. The measurement Committee of the American urological association. $J$ Urol 1992;148:1549-57.

23 Papantoniou K, Castaño-Vinyals G, Espinosa A, et al. Night shift work, chronotype and prostate cancer risk in the MCC-Spain casecontrol study. Int J Cancer 2015;137:1147-57.

24 Kogevinas M, Espinosa A, Papantoniou K, et al. Prostate cancer risk decreases following cessation of night shift work. Int J Cancer 2019;145:2597-9.

25 Gómez-Acebo I, Dierssen-Sotos T, Palazuelos C, et al. The use of antihypertensive medication and the risk of breast cancer in a casecontrol study in a Spanish population: the MCC-Spain study. PLoS One 2016;11:e0159672-14.

26 Castelló A, Boldo E, Pérez-Gómez B, et al. Adherence to the Western, Prudent and Mediterranean dietary patterns and breast cancer risk: MCC-Spain study. Maturitas 2017;103:8-15.

27 Dierssen-Sotos T, Gómez-Acebo I, Palazuelos C, et al. Validating a breast cancer score in Spanish women. The MCC-Spain study. Sci Rep 2018;8:1-8.

28 Ibáñez-Sanz G, Díez-Villanueva A, Alonso MH, et al. Risk model for colorectal cancer in Spanish population using environmental and genetic factors: results from the MCC-Spain study. Sci Rep 2017;7:43263.

29 Romaguera D, Gracia-Lavedan E, Molinuevo A, et al. Adherence to nutrition-based cancer prevention guidelines and breast, prostate and colorectal cancer risk in the MCC-Spain case-control study. Int. J. Cancer 2017;141:83-93.

30 Hill HA, Kleinbaum DG. Encyclopedia of epidemiologic methods. In: Gail MH, Benichou J, eds. Encyclopedia of epidemiologic methods. Wiley, 2000: 92-3. 